\title{
Prostaglandins Inhibit Renal Ammoniagenesis in the Rat
}

\author{
Edward R. Jones, Thomas R. Beck, Shiv Kapoor, \\ Robert Shay, and Robert G. Narins \\ Departments of Medicine and Physiology, Section of Nephrology, \\ Temple University Health Sciences Center, \\ Philadelphia, Pennsylvania 19140
}

bstract. We describe the inhibitory effect of prostaglandins (PGs) on in vivo rat renal ammonia synthesis. The influence of systemic $\mathrm{pH}$ upon urinary PG excretion and ammoniagenesis was also investigated. Finally, PG production by incubated rat renal cortical slices was suppressed to investigate the PG-ammonia interplay in the absence of changes in renal blood flow, glomerular filtration rate, ambient electrolyte concentrations or extrarenal hormonal factors.

In vivo ammonia synthesis doubled and PG excretion fell by $44 \%$ in normal rats, after intravenous administration of $1 \mathrm{mg} / \mathrm{kg}$ of meclofenamate. Higher doses of meclofenamate further augmented ammonia production and further reduced PG excretion. PG depletion was also associated with an increase in fractional excretion of ammonia $\left(\mathrm{FE}_{\mathrm{NH}_{3}}\right)$ that was independent of changes in urine flow rate or $\mathrm{pH}$.

Acute metabolic acidosis (AMA) increased total ammonia synthesis but also stimulated PG production. Administration of meclofenamate to rats with mild AMA markedly reduced urinary PG excretion, further augmented ammonia synthesis, and significantly increased the $\mathrm{FE}_{\mathrm{NH}_{3}}$. Inhibition of stimulated PG synthesis during severe AMA did not increase ammoniagenesis or $\mathrm{FE}_{\mathrm{NH}_{3}}$. Acute metabolic alkalosis did not alter production of PGs or ammonia, but reduced the $\mathrm{FE}_{\mathrm{NH}_{3}}$ by

A preliminary abstract was presented at the Annual Meeting of The American Federation for Clinical Research, 1983 (1983. Clin. Res. $31: 431 A$ ) and reported at the National Meetings of The American Society of Nephrology, 1982.

Dr. Jones is a recipient of a Clinical Investigator Award of the National Institutes of Health.

Received for publication 19 December 1983 and in revised form 8 May 1984.

J. Clin. Invest.

(c) The American Society for Clinical Investigation, Inc. 0021-9738/84/09/0992/11 $\$ 1.00$

Volume 74, September 1984, 992-1002
42\%. Meclofenamate nearly normalized the $\mathrm{FE}_{\mathrm{NH}_{3}}$ but stimulated synthesis to a lesser degree than was seen in nonalkalotic rats that received meclofenamate.

Inhibition of PG synthesis in incubated rat renal cortical slices also stimulated ammoniagenesis. Conversely, stimulation of PG synthesis decreased ammonia production and acidification of the incubation medium increased prostaglandin $F_{2 \alpha}$ production. Thus, in vitro findings support the in vivo results.

We conclude that PGs inhibit ammonia synthesis in normal rats and in those undergoing mild AMA. Severe acidosis overrides this inhibitory effect of PGs, whereas metabolic alkalosis suppresses the stimulatory effect of PG synthesis inhibition.

\section{Introduction}

Prostaglandins (PGs)' modulate many vital renal functions. Their effects on renal blood flow (RBF), glomerular filtration rate (GFR), water metabolism, and sodium handling have been extensively studied and recently reviewed (1). PGs appear to function primarily as negative-feedback inhibitors, i.e., the renal response elicited by various physiologic and pathologic stimuli appears to be the net result of a positive direct tissue effect of the stimulus plus the negative indirect inhibitory action of stimulated PG synthesis. These interactions are best illustrated by the effect of antidiuretic hormone (ADH) on renal water reabsorption. ADH enhances water reabsorption in the distal nephron and toad urinary bladder, but concomitantly stimulates PG synthesis, which in turn, reduces the hydro-osmotic effect of the hormone $(2,3)$. Prevention of ADH-stimulated PG synthesis enhances water reabsorption by unmasking the full, unopposed effect of the hormone (3).

Although a number of physiologic perturbations are known to influence renal ammoniagenesis (4), the effects of PGs on

1. Abbreviations used in this paper: $\mathrm{ADH}$, antidiuretic hormone; AMA, acute metabolic acidosis; $\mathrm{FE}_{\mathrm{NH}_{3}}$, fractional excretion of $\mathrm{NH}_{3}$; GFR, glomerular filtration rate; KHB, Krebs-Henseleit bicarbonate buffer; mAMA, mild AMA; PG, prostaglandin; PGE $_{2}$ and $\mathrm{PGF}_{2 \alpha}$, prostaglandins $E_{2}$ and $F_{2 \alpha} ; R B F$, renal blood flow; sAMA, severe AMA. 
this key urinary buffer have not been previously investigated. Many studies have demonstrated that acidification of the serosal medium of the toad bladder inhibits the action of ADH (5-9). Recently, Forrest et al. (9) confirmed these results and demonstrated that acidification of the medium is also associated with increased prostaglandin $\mathrm{E}_{2}\left(\mathrm{PGE}_{2}\right)$ production. The addition of meclofenamate or indomethacin, inhibitors of PG production, to acidified bladders restored the effect of $\mathrm{ADH}$. In vivo studies by Beck and $\mathrm{Kim}(10)$ demonstrated that rats with acute metabolic acidosis (AMA) had a diminished response to physiologic amounts of $\mathrm{ADH}$, i.e., free water reabsorption was diminished. Together, these studies clearly demonstrate a potentially important interplay between acidosis and renal PG synthesis.

The purpose of the present study was to define the influence of PGs on renal ammonia synthesis in vivo and in vitro under normal conditions and during various acid-base perturbations. We demonstrate that PGs are potent inhibitors of the renal synthesis of this important buffer. This conclusion is based on the following observations. Inhibition of PG synthesis markedly stimulated renal ammoniagenesis in normal rats. Mild acute metabolic acidosis (mAMA) simultaneously stimulated renal PG synthesis and ammoniagenesis. Inhibition of acidosisinduced PG production further enhanced ammonia generation. However, the inhibitory effect of PGs was completely overridden by severe metabolic acidosis (sAMA), while metabolic alkalosis dampened the stimulatory effect of inhibited PG synthesis. The physiologic and pathophysiologic implications of these findings are discussed.

\section{Methods}

Rat chow and drinking water were given ad lib. to male SpragueDawley rats $(275-375 \mathrm{~g})$ before study.

\section{In vivo studies}

Clearance methods (Fig. 1). Rats, anesthetized with intraperitoneal inactin $(150 \mathrm{mg} / \mathrm{kg})$ were tracheotomized and ventilated with a small animal respirator (Harvard Apparatus Co., Inc., S. Natick, MA), which maintained $\mathrm{PCO}_{2}$ at $40 \pm 2$ torr. Adjustments in tidal volume were only made during the equilibration period (Fig. 1). The jugular vein was catheterized with PE 50 tubing for infusion and a similar carotid artery catheter was connected to a Statham transducer for monitoring blood pressure and for sampling blood for acid-base parameters. A suprapubic cystotomy was performed and flared PE 50 tubing was inserted for collection of urine. After a midline incision, the abdomen was closed with staples to facilitate subsequent access to the renal vein. After preparative surgery, each rat received a bolus injection of normal saline equal to $1 \%$ of body weight. The saline contained $10 \mu \mathrm{Ci}$ of $\left[{ }^{3} \mathrm{H}\right] \mathrm{inulin}$, the extraction and clearance of which was used to measure RBF and GFR (11). A constant infusion $(0.11 \mathrm{ml} / \mathrm{min})$ of $0.45 \%$ saline that contained $2.5 \%$ mannitol and $\left[{ }^{3} \mathrm{H}\right]$ inulin $(10 \mu \mathrm{Ci} / \mathrm{h})$ was maintained throughout the study, unless otherwise noted. A 70-min equilibration period was followed by a 40-min experimental period, during the last 10 min of which urine was collected into preweighed conical vials. At the end of the experiment, $1.5 \mathrm{ml}$ of renal venous blood was slowly aspirated via a 27 -gauge curved needle on a heparinized syringe; 2.0 $\mathrm{ml}$ of arterial blood was then aspirated (12).

Urine was analyzed for $\mathrm{pH}$, total $\mathrm{CO}_{2}$, ammonia, $\mathrm{PGE}_{2}$ and prostaglandin $\mathrm{F}_{2 \alpha}\left(\mathrm{PGF}_{2 \alpha}\right)$, and [ $\left.{ }^{3} \mathrm{H}\right]$ inulin. Hematocrit, $\mathrm{pH}$, total $\mathrm{CO}_{2}$, ammonia, and $\left[{ }^{3} \mathrm{H}\right]$ inulin were measured on arterial blood, while renal venous blood was only assayed for ammonia and $\left[{ }^{3} \mathrm{H}\right]$ inulin.

\section{EXPERIMENTAL PROTOCOL}



Figure 1. Outline of the protocol for the in vivo clearance studies performed in male Sprague-Dawley rats divided into PG INTACT (unhatched) and PG DEPLETE (hatched) groups. Meclofenamate (1 or $5 \mathrm{mg} / \mathrm{kg}$ ), indomethacin ( 5 $\mathrm{mg} / \mathrm{kg}$ ), or their respective vehicles were administered at the indicated times. Each group was subdivided as noted. All infusions contained $2.5 \%$ mannitol and $\left[{ }^{3} \mathrm{H}\right]$ inulin and were delivered at a rate of 0.11 $\mathrm{ml} / \mathrm{min}$. In those subgroups undergoing acid-base perturbations, the saline was replaced isotonically by $\mathrm{HCl}$ or $\mathrm{NaHCO}_{3}$. 


\section{Alterations in $P G$ synthesis}

Preliminary experiments. Using anesthetized, ventilated rats, we determined the point at which maximal inhibition of PG synthesis occurred and the duration of this suppression. After collection of urine for 20 min, a single dose of $5 \mathrm{mg} / \mathrm{kg}$ of meclofenamate, dissolved in $0.15 \mathrm{M}$ $\mathrm{NaCl}$, was given intravenously. Urine was collected for five additional 20-min periods after the meclofenamate injection. PGs were then measured in all urine samples.

Meclofenamate administration (Fig. 1). Meclofenamate, $5 \mathrm{mg} / \mathrm{kg}$ body weight (high dose) or $1 \mathrm{mg} / \mathrm{kg}$ body weight (low dose), was given $60 \mathrm{~min}$ before urine and blood collection. As determined in preliminary experiments, $5 \mathrm{mg} / \mathrm{kg}$ resulted in unmeasurable $P G$ excretion within $20 \mathrm{~min}$ of injection. Animals receiving meclofenamate were designated as "PG-deplete rats." Animals designated as "PG-intact rats," received the vehicle (saline) intravenously, $60 \mathrm{~min}$ before urine and blood collections.

Indomethacin administration. Additional studies were carried out with indomethacin, another cyclooxygenase inhibitor that differs structurally from meclofenamate. The drug, $5 \mathrm{mg} / \mathrm{kg}$ body weight, was solubilized in sodium carbonate and administered intravenously to normal rats in a fashion identical to that noted above. Control rats received vehicle alone.

\section{Alteration in systemic $\mathrm{pH}$}

The acid-base perturbations described below were produced during the experimental period in PG-intact and -depleted rats.

Normal acid-base status. The mannitol-saline solution, initiated during the equilibration period, was continued at the same rate throughout the experimental period.

$A M A$. The mannitol-saline solution infused during the equilibration period was changed to a mannitol-hydrochloric acid solution that provided $2 \mathrm{mmol}$ of acid/ $\mathrm{kg}$ of body weight during the $40-\mathrm{min}$ experimental period. These animals represent mild AMA. A second subgroup, which received $4 \mathrm{mmol}$ of hydrochloric acid/kg body weight of hydrochloric acid during the experimental period, was designated severe AMA.

Acute metabolic alkalosis. The mannitol-saline solution was changed to $0.4 \mathrm{M}$ sodium bicarbonate, which was infused during the $40-\mathrm{min}$ experimental period and provided $2 \mathrm{mmol}$ of alkali/kg body weight.

\section{In vitro studies}

Rat renal cortical slices were obtained as previously described (13). Slices taken from two rats were mixed and randomly placed in $25-\mathrm{ml}$ Erlenmeyer flasks that contained $10 \mathrm{ml}$ of Krebs-Henseleit bicarbonate buffer (KHB) containing (in millimolar): $\mathrm{NaCl}, 115 ; \mathrm{KCl}, 5 ; \mathrm{MgSO}_{4}$, 1.2; $\mathrm{CaCl}_{2}, 1 ; \mathrm{NaHCO}_{3}, 24 ; \mathrm{KH}_{2} \mathrm{PO}_{4}, 1.2$; and glutamine, 2. Control flasks were glutamine-free. Media were separately designated: "PG intact": vehicle was added to the KHB; "PG inhibited": meclofenamate $(20 \mu \mathrm{g} / \mathrm{ml})$ was dissolved in water and added to KHB; in separate experiments, indomethacin $(25 \mu \mathrm{g} / \mathrm{ml})$ was added to 12 flasks that contained KHB. Equal volumes of diluent were added to the control flasks; "PG excess": Calcium ionophore A23187 $(19 \mu \mathrm{M})$ was dissolved in ethanol and added to KHB to stimulate PG synthesis. Paired control flasks received the appropriate vehicle. The incubation media and slices were gassed with $5 \% \mathrm{CO}_{2}: 95 \% \mathrm{O}_{2}$, which resulted in a pH of 7.4. The flasks were placed in a Dubanoff metabolic shaker for $60 \mathrm{~min}$ at $37^{\circ} \mathrm{C}$. Aliquots of the medium were obtained $5 \mathrm{~min}$ after initiation of incubation and again at $65 \mathrm{~min}$ and then analyzed for PGs and ammonia. Samples for ammonia were deproteinized with perchloric acid while the remainder of the media was stored at $-80^{\circ} \mathrm{C}$ until analyzed for PGs. The slices were desiccated at $110^{\circ} \mathrm{C}$ for $24 \mathrm{~h}$, and then weighed. Acidosis (pH 7.0) was established by reducing the concentration of $\mathrm{HCO}_{3}^{-}$to $12 \mathrm{mM}$ while reciprocally increasing that of chloride.

\section{Measurements}

Ammonia. Plasma and urinary ammonia were determined by a modification of the method of Kurahasi et al. (14). The technique uses a Dowex (50 $\times 8$ [200 mesh]) resin in the sodium form, which is placed in Pasteur pipettes that are plugged with glass wool. Plasma and urinary ammonia bind to the column and are then eluted with $4 \mathrm{M}$ $\mathrm{NaCl}$. Ammonia from eluted blood and urine and from precipitated KHB media was determined colorimetrically, by using a spectrophotometer (Perkin-Elmer Corp., Instrument Div., Norwalk, CT) (15). Recoveries of ammonia added to plasma, urine, and incubation media was $98 \pm 3 \%$. Measurements were performed in duplicate and the mean values were used for statistical analysis.

PGs. $\mathrm{PGE}_{2}$ and $\mathrm{PGF}_{2 \alpha}$ were measured by radioimmunoassay by using standard techniques (16). Urine samples that contained tracer amounts of radioactive PGs for recoveries were acidified to $\mathrm{pH}$ 3.03.5 and extracted twice with $3 \mathrm{ml}$ of ethylacetate. The organic phase from the extraction was evaporated to dryness and resuspended in ethylacetate/toluene. The samples were then purified on silicic acid columns. The PG fraction, eluted with toluene/ethylacetate/methanol, was evaporated and resuspended in buffer. $\mathrm{PGE}_{2}$ and $\mathrm{PGF}_{2 \alpha}$ were then measured by radioimmunoassay. $\mathrm{PGE}_{2}$ and $\mathrm{PGF}_{2 \alpha}$ were measured by radioimmunoassay on unextracted $\mathrm{KHB}$. The antibody to $\mathrm{PGE}_{2}$ was purchased from Sigma Chemical Co. (St. Louis, MO), while that to $\mathrm{PGF}_{2 \alpha}$ was a generous gift from Dr. M. Dunn, Case Western Reserve University (Cleveland, $\mathrm{OH}$ ). The sensitivities of the antisera were: $\mathrm{PGE}_{2}: 25 \mathrm{pg} / \mathrm{ml} ; \mathrm{PGF}_{2 \alpha}: 50 \mathrm{pg} / \mathrm{ml}$. Samples were run in triplicate and the final data were corrected for recovery. Recoveries ranged from 65 to $80 \%$ of the added tracer PGs.

Arterial and urine pH. A Radiometer pH meter (Copenhagen Radiometer pH Meter 27 with expanded scale) was used to anaerobically measure $\mathrm{pH}$. Total $\mathrm{CO}_{2}$ was determined manometrically with a Natelson microgasometer; bicarbonate and $\mathrm{PCO}_{2}$ were calculated by using the Henderson-Hasselbalch equation. The $\mathrm{p} K^{\prime}$ was corrected for temperature and the solubility coefficient, $0.0301 \mathrm{mmol} \mathrm{CO} /$ torr, was used.

$G F R$ and $R B F$. The GFR was determined by standard calculations, by using $\left[{ }^{3} \mathrm{H}\right]$ inulin. The renal plasma flow was determined from the clearance of inulin corrected by the Wolf equation (17) and divided by the renal extraction of inulin (11). The RBF was calculated by dividing the RPF by $[1$ - hematocrit].

\section{Calculations}

Ammonia. In vivo total ammonia production was calculated as the product of the RBF and the renal venous, arterial plasma difference in ammonia concentration, plus the urinary excretion of ammonia. Production is expressed as nanomoles per minute per milliliter GFR. Fractional excretion of ammonia $\left(\mathrm{FE}_{\mathrm{NH}_{3}}\right)$ refers to the fraction of renal ammonia synthesized that appears in the urine or $\left\{\mathrm{U}_{\mathrm{NH}_{3}} \mathrm{~V}\right.$ $\left.\div\left[U_{\mathrm{NH}_{3}} \mathrm{~V}+\left(\mathrm{RV}_{\mathrm{NH}_{3}}-\mathrm{A}_{\mathrm{NH}_{3}} \times \mathrm{RBF}\right)\right]\right\} 100$, where $\mathrm{U}$ is urine, $\mathrm{V}$ is volume, and $\mathrm{RV}_{\mathrm{NH}_{3}}-\mathrm{A}_{\mathrm{NH}_{3}}$ is renal venous, arterial difference in $\mathrm{NH}_{3}$ concentration.

In vitro production was calculated as the difference in ammonia accumulation over $60 \mathrm{~min}$ between slice-containing flasks with and without glutamine. The addition of ammonia to the incubation medium derives from the spontaneous non-tissue-mediated breakdown 
of glutamine, from that carried into the medium with renal tissue, and finally from that generated by tissue from glutamine during the experimental period of incubation. Accordingly, the flask ammonia content at $5 \mathrm{~min}$ of incubation was subtracted from the value found at $65 \mathrm{~min}$ for flasks containing tissue slices with $2 \mathrm{mM}$ glutamine and for those flasks with glutamine but without tissue. The ammonia contributed by spontaneous amino acid breakdown was subtracted. Ammonia synthesis was expressed as micromoles per gram of tissue dry weight per hour.

Prostaglandins. In vitro PG synthesis was determined by subtracting the media content of PG production at the end of $5 \mathrm{~min}$ of incubation from PGs producted after a 65-min incubation and expressed as picograms per gram dry weight per hour.

Statistical analyses. All results are expressed as the mean \pm 1 SE. When indicated, analysis of variance was performed to sort out intragroup significance. Statistical differences were determined by paired and unpaired $t$ tests. Linear regression was determined by the method of least squares. Statistical comparisons of estimated parameters of the best-fit line were made by using the $t$ test (18).

Medications and chemicals. Indomethacin (Sigma Chemical Co.), meclofenamate (Parke-Davis, Morris Plains, NJ), and calcium ionophore A23187 (Sigma Chemical Co.) were used in this study.

\section{Results}

In vivo studies

Preliminary studies. Within $20 \mathrm{~min}$ of the intravenous administration of $5 \mathrm{mg} / \mathrm{kg}$ of meclofenamate, urinary excretion of $\mathrm{PGE}_{2}$ and $\mathrm{PGF}_{2 \alpha}$ was unmeasurable (i.e., $<20 \mathrm{pg} / \mathrm{min}$ ). This extinction of PG synthesis was maintained for at least 100 min. Therefore, in studies of PG-depleted rats, meclofenamate administration preceeded the experimental period by $30 \mathrm{~min}$.

Dose-response effect of meclofenamate in normal rats. Hemodynamic and acid-base parameters in all groups are outlined in Tables I and II.

$P G$-intact rats. Total ammonia production was $281 \pm 19$ $\mathrm{nmol} / \mathrm{min}$ per $\mathrm{ml} \mathrm{GFR}$ with $140 \pm 13 \mathrm{nmol} / \mathrm{min}$ per $\mathrm{ml} \mathrm{GFR}$ added to renal venous blood and $140 \pm 13 \mathrm{nmol} / \mathrm{min}$ per $\mathrm{ml}$ GFR added to the urine. Therefore, the $\mathrm{FE}_{\mathrm{NH}_{3}}$ was $50 \pm 5 \%$. $\mathrm{PGE}_{2}$ and $\mathrm{PGF}_{2 \alpha}$ excretion in normal rats were $87 \pm 7 \mathrm{pg} / \mathrm{min}$ and $191 \pm 19 \mathrm{pg} / \mathrm{min}$, respectively. Extrapolation of these data to $24 \mathrm{~h}$ yields values comparable to those reported by others for rats undergoing balance studies (19).

Low-dose meclofenamate $(1 \mathrm{mg} / \mathrm{kg})$. Administration of low-dose meclofenamate had no hemodynamic effect nor were urinary or arterial acid-base parameters significantly altered. Arterial and renal venous ammonia concentrations were unchanged, while the renal venous, arterial ammonia difference was increased when compared with PG-intact rats. Total ammonia production significantly increased from $281 \pm 19$ to $591 \pm 46 \mathrm{nmol} / \mathrm{min}$ per $\mathrm{ml} \mathrm{GFR}(P<0.01)$, pari passu with the diminished PG synthesis (Fig. 2). While ammonia addition to the renal vein and urine both increased, the urinary component rose proportionately more, with $\mathrm{FE}_{\mathrm{NH}_{3}}$ increasing from $50 \pm 5$ in controls to $61 \pm 5 \%$ in PG-depleted rats $(P<0.05)$. The enhancement of the $\mathrm{FE}_{\mathrm{NH}_{3}}$ was independent of changes
Table I. Clearance Studies: Acid-Base Parameters, In Vivo Ammonia and PG

Production in Rats with Normal Acid-Base Status

\begin{tabular}{|c|c|c|c|}
\hline \multirow[b]{2}{*}{$\begin{array}{l}\text { Physiologic and chemical } \\
\text { parameters }\end{array}$} & \multirow[b]{2}{*}{$\begin{array}{l}\text { PG-intact } \\
(11)^{*}\end{array}$} & \multicolumn{2}{|c|}{$\begin{array}{l}\text { Meclofenamate-induced } \\
\text { PG depletion }\end{array}$} \\
\hline & & $\begin{array}{l}\text { Meclo } \\
1 / \mathrm{mg} / \mathrm{kg} \\
(12)\end{array}$ & $\begin{array}{l}\text { Meclo } \\
5 \mathrm{mg} / \mathrm{kg} \\
(9)\end{array}$ \\
\hline \multicolumn{4}{|l|}{$\begin{array}{l}\text { Clearance and acid-base } \\
\text { parameters }\end{array}$} \\
\hline $\mathrm{C}_{\mathrm{IN}}(\mathrm{ml} / \mathrm{min}$ per $0.1 \mathrm{~kg})$ & $1.05 \pm 0.04$ & $0.98 \pm 0.05$ & $0.89 \pm 0.08 \S$ \\
\hline $\mathrm{RBF}(\mathrm{ml} / \mathrm{min}$ per $0.1 \mathrm{~kg})$ & $4.81 \pm 0.25$ & $4.56 \pm 0.29$ & $3.78 \pm 0.95$ \\
\hline Vol $(\mu l / m i n)$ & $66 \pm 10$ & $73 \pm 10$ & $35 \pm 5^{11}$ \\
\hline Urine $\mathrm{pH}$ & $6.35 \pm 0.10$ & $6.48 \pm 0.21$ & $6.49 \pm 0.13$ \\
\hline Arterial pH & $7.39 \pm 0.01$ & $7.40 \pm 0.01$ & $7.40 \pm 0.01$ \\
\hline $\mathrm{HCO}_{3}(m M)$ & $22.9 \pm 0.5$ & $22.8 \pm 0.54$ & $22.1 \pm 0.5$ \\
\hline $\mathrm{PCO}_{2}$ (torr) & $38.4 \pm 1.3$ & $38.7 \pm 1.1$ & $36.3 \pm 1.4$ \\
\hline \multicolumn{4}{|l|}{$\begin{array}{c}\text { Ammonia and PG } \\
\text { production }\end{array}$} \\
\hline Arterial $\left[\mathrm{NH}_{3}\right](\mathrm{nmol} / \mathrm{ml})$ & $69 \pm 5$ & $61 \pm 4$ & $68 \pm 11$ \\
\hline \multicolumn{4}{|l|}{ Renal venous $\left[\mathrm{NH}_{3}\right]$} \\
\hline$(\mathrm{nmol} / \mathrm{ml})$ & $100 \pm 6$ & $110 \pm 7$ & $135 \pm 15 \S$ \\
\hline $\mathrm{RV}-\mathrm{A}\left[\mathrm{NH}_{3}\right](\mathrm{nmol} / \mathrm{ml})$ & $31 \pm 2$ & $49 \pm 7 \S$ & $65 \pm 13^{11}$ \\
\hline $\mathrm{NH}_{3}$ added to $\mathrm{RV} \ddagger$ & $140 \pm 13$ & $227 \pm 26 \S$ & $283 \pm 58^{\prime \prime}$ \\
\hline Urinary excretion $\mathrm{NH}_{3} \ddagger$ & $140 \pm 13$ & $354 \pm 20^{\prime \prime}$ & $483 \pm 58^{\prime \prime}$ \\
\hline Total $\mathrm{NH}_{3}$ production $\ddagger$ & $281 \pm 19$ & $591 \pm 46^{\prime \prime}$ & $766 \pm 87^{\prime \prime}$ \\
\hline $\mathrm{FE}_{\mathrm{NH}_{3}}(\%)$ & $50 \pm 5$ & $61 \pm 5 \S$ & $63 \pm 8 \S$ \\
\hline \multicolumn{4}{|l|}{ PG excretion (pg/min) } \\
\hline $\mathrm{PGF}_{2 \alpha}$ & $191 \pm 19$ & $84 \pm 4^{\prime \prime}$ & UD" \\
\hline $\mathrm{PGE}_{2}$ & $87 \pm 7$ & $34 \pm 5^{\prime \prime}$ & UD' \\
\hline
\end{tabular}

All data are expressed as means $\pm \mathrm{SE}$. $\mathbf{R V}-\mathrm{A}\left[\mathrm{NH}_{3}\right]$, renal venous, arterial difference in ammonia concentration; $C_{\mathrm{IN}}$, clearance of inulin; Meclo, meclofenamate, RV, renal vein; UD, undetectable; Vol, urine volume.

* No. of rats in each group.

‡ Values expressed in nanomoles per minute per milliliter GFR (means \pm SE).

$\| P<0.01 ; \S P<0.05$. $P$-values refer to differences between PG-intact and PG-depleted rats.

in urinary $\mathrm{pH}$ or urine flow rates. $\mathrm{PGE}_{2}$ and $\mathrm{PGF}_{2 \alpha}$ synthesis were each decreased by $44 \%(P<0.01)$, to $34 \pm 5$ and $84 \pm 4$ $\mathrm{pg} / \mathrm{min}$, respectively.

High-dose meclofenamate $(5 \mathrm{mg} / \mathrm{kg}$ ). The GFR and RBF were reduced by high-dose meclofenamate to $\sim 80 \%$ of values found in normal controls and rats receiving low-dose $(1 \mathrm{mg} /$ $\mathrm{kg}$ ) meclofenamate. There were no changes in mean arterial pressure, or in urinary or arterial acid-base parameters (Table I). High-dose meclofenamate increased the rate of addition of 
Table II. Clearance Studies: Acid-Base Parameters, Ammonia, and PG Production in Rats with Metabolic Acidosis and Alkalosis

\begin{tabular}{|c|c|c|c|c|c|c|}
\hline \multirow[b]{3}{*}{ Physiologic and chemical parameters } & \multicolumn{4}{|l|}{ AMA } & & \\
\hline & \multicolumn{2}{|l|}{ Mild acidosis } & \multicolumn{2}{|c|}{ Severe acidosis } & \multicolumn{2}{|c|}{ Acute metabolic alkalosis } \\
\hline & $\begin{array}{l}\text { PG-intact } \\
(7)^{*}\end{array}$ & $\begin{array}{l}\text { PG-deplete } \\
\text { (11) }\end{array}$ & $\begin{array}{l}\text { PG-intact } \\
\text { (13) }\end{array}$ & $\begin{array}{l}\text { PG-deplete } \\
\text { (8) }\end{array}$ & $\begin{array}{l}\text { PG-intact } \\
\text { (6) }\end{array}$ & $\begin{array}{l}\text { PG-deplete } \\
\text { (7) }\end{array}$ \\
\hline \multicolumn{7}{|l|}{$\begin{array}{l}\text { Clearance and acid-base } \\
\text { parameters }\end{array}$} \\
\hline $\mathrm{C}_{\mathrm{IN}}(\mathrm{ml} / \mathrm{min}$ per $0.1 \mathrm{~kg})$ & $0.79 \pm 0.08$ & $0.91 \pm 0.07$ & $0.89 \pm 0.07$ & $0.85 \pm 0.08$ & $0.90 \pm 0.02$ & $0.93 \pm 0.06$ \\
\hline $\mathrm{RBF}(\mathrm{ml} / \mathrm{min}$ per $0.1 \mathrm{~kg})$ & $3.70 \pm 0.27$ & $4.48 \pm 0.63$ & $3.93 \pm 0.32$ & $4.53 \pm 0.54$ & $4.90 \pm 0.42$ & $4.49 \pm 0.45$ \\
\hline $\mathrm{Vol}(\mu \mathrm{l} / \mathrm{min})$ & $46 \pm 10$ & $33 \pm 6 \S$ & $49 \pm 9$ & $23 \pm 2 \S$ & $103 \pm 23$ & $67 \pm 11 \S$ \\
\hline Urine $\mathrm{pH}$ & $6.02 \pm 0.13$ & $6.28 \pm 0.16$ & $5.77 \pm 0.08$ & $6.11 \pm 0.05 \S$ & $7.73 \pm 0.22$ & $7.45 \pm 0.04$ \\
\hline Arterial pH & $7.29 \pm 0.01$ & $7.32 \pm 0.01$ & $7.23 \pm 0.02$ & $7.23 \pm 0.01$ & $7.53 \pm 0.01$ & $7.50 \pm 0.01$ \\
\hline $\mathrm{HCO}_{3}(m M)$ & $18.0 \pm 0.4$ & $19.8 \pm 0.9$ & $14.2 \pm 0.8$ & $13.9 \pm 0.8$ & $31.8 \pm 0.8$ & $32.4 \pm 0.4$ \\
\hline $\mathrm{PCO}_{2}$ (torr) & $38.2 \pm 1.1$ & $38.0 \pm 1.6$ & $34.7 \pm 1.5$ & $34.2 \pm 2.1$ & $40.4 \pm 1.3$ & $39.5 \pm 1.1$ \\
\hline \multicolumn{7}{|l|}{ Ammonia and PG production } \\
\hline Arterial $\left[\mathrm{NH}_{3}\right](\mathrm{nmol} / \mathrm{ml})$ & $95 \pm 8$ & $56 \pm 8 \S$ & $101 \pm 12$ & $91 \pm 17$ & $38 \pm 12$ & $63 \pm 8 \S$ \\
\hline Renal venous $\left[\mathrm{NH}_{3}\right](\mathrm{nmol} / \mathrm{ml})$ & $165 \pm 14$ & $126 \pm 7 \S$ & $165 \pm 13$ & $168 \pm 15$ & $93 \pm 17$ & $127 \pm 11 \S$ \\
\hline $\mathrm{RV}-\mathrm{A}\left[\mathrm{NH}_{3}\right](\mathrm{nmol} / \mathrm{ml})$ & $70 \pm 9$ & $70 \pm 14$ & $54 \pm 11$ & $77 \pm 12$ & $55 \pm 6$ & $64 \pm 8$ \\
\hline $\mathrm{NH}_{3}$ added to $\mathrm{RV} \ddagger$ & $302 \pm 59$ & $350 \pm 53$ & $350 \pm 57$ & $349 \pm 33$ & $234 \pm 33$ & $234 \pm 48$ \\
\hline Urinary excretion $\mathrm{NH}_{3} \ddagger$ & $315 \pm 35$ & $503 \pm 50^{\prime \prime}$ & $483 \pm 60$ & $503 \pm 67$ & $96 \pm 7$ & $183 \pm 48 \S$ \\
\hline Total $\mathrm{NH}_{3}$ production $\ddagger$ & $617 \pm 67$ & $853 \pm 88 \S$ & $833 \pm 102$ & $852 \pm 74$ & $330 \pm 29$ & $417 \pm 38 \S$ \\
\hline $\mathrm{FE}_{\mathrm{NH}_{3}}(\%)$ & $51 \pm 3$ & $59 \pm 4 \S$ & $58 \pm 3$ & $59 \pm 6$ & $29 \pm 6$ & $44 \pm 5^{\prime \prime}$ \\
\hline \multicolumn{7}{|l|}{ PG excretion (pg/min) } \\
\hline $\mathrm{PGF}_{2 \alpha}$ & $695 \pm 178$ & $68 \pm 11^{11}$ & $545 \pm 81$ & $67 \pm 13^{\prime \prime}$ & $176 \pm 39$ & UD" \\
\hline $\mathrm{PGE}_{2}$ & $256 \pm 42$ & $51 \pm 9^{\prime \prime}$ & $336 \pm 18$ & $29 \pm 8^{\prime \prime}$ & $59 \pm 22$ & UD $^{\prime \prime}$ \\
\hline
\end{tabular}

Abbreviations and symbols as in Table I. PG depletion was induced with the intravenous infusion of $5 \mathrm{mg} / \mathrm{kg}$ of meclofenamate.

ammonia to the renal vein to values that significantly exceeded those in normal controls. While the rate of ammonia addition to the renal vein exceeded that found in rats receiving low-

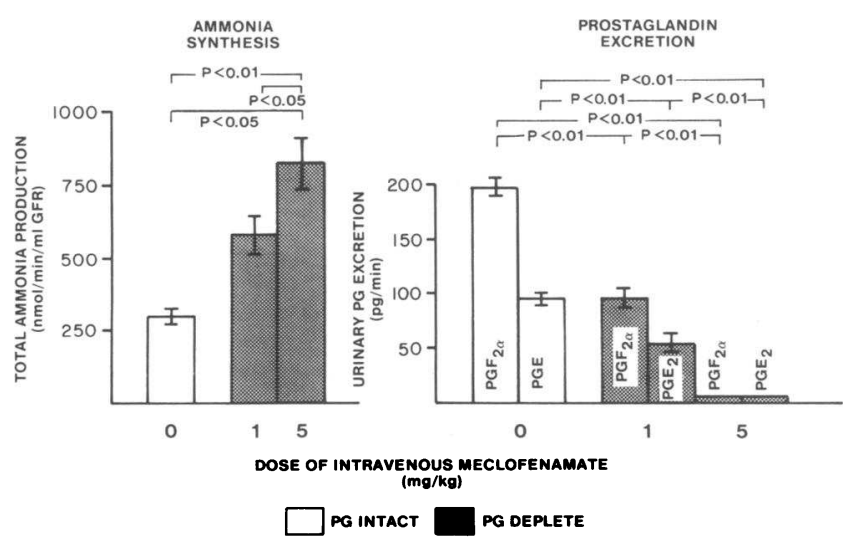

Figure 2. Response of renal ammoniagenesis to increasing doses of meclofenamate. Differences in ammonia production and PG excretion are indicated above the bars. dose meclofenamate, the difference was not statistically significant (Table I). The urinary excretion of ammonia, however, was significantly greater in rats on high-dose drug than in those receiving low dose $(P<0.05)$. Thus, total ammonia synthesis was increased by high-dose meclofenamate $(766 \pm 87$ $\mathrm{nmol} / \mathrm{min}$ per $\mathrm{ml} \mathrm{GFR}$ ) to values in excess of those found in rats given low dose meclofenamate $(591 \pm 46 \mathrm{nmol} / \mathrm{min}$ per $\mathrm{ml}$ GFR; $P<0.05$ ). The $\mathrm{FE}_{\mathrm{NH}_{3}}$ was increased by meclofenamate but the increment was not dose dependent. Again, the meclofenamate-induced increase in the $\mathrm{FE}_{\mathrm{NH}_{3}}$ was independent of any change in urinary $\mathrm{pH}$ or flow rate. The increased production of ammonia and decreased production of PGs that were elicited by increasing doses of meclofenamate is depicted in Fig. 2. The negative-inverse relationship between ammonia synthesis and PG production achieved high degrees of statistical significance: $y=-2.44 x+776 ; r=0.78(P<0.01)$ for PGF $_{2 \alpha}$ and $y=-4.6 x+741 ; r=-0.65(P<0.01)$ for $\mathrm{PGE}_{2}$ (Fig. 3).

Indomethacin-treated normal rats. To reduce the possibility that the ammoniagenic response to meclofenamate was a nonspecific chemical effect unrelated to PG inhibition, indomethacin, a structurally dissimilar inhibitor, was studied. Five 


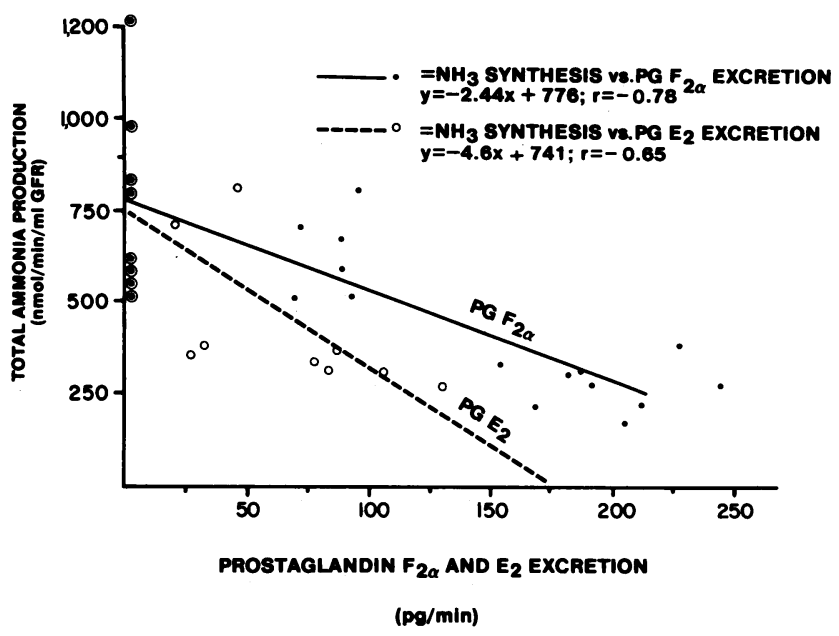

Figure 3. Relationship between total ammonia production and urinary PG excretion. (๑), $\mathrm{PGF}_{2 \alpha} ;$ (०), $\mathrm{PGE}_{2} ;(0)$, overlapping values of $\mathrm{NH}_{3}$ production when both PGs were undetectable. The slopes are significantly different from each other $(P<0.05)$ and the correlation coefficients are significant $(P<0.01)$.

rats received $5 \mathrm{mg} / \mathrm{kg}$ of indomethacin i.v., $60 \mathrm{~min}$ before urine and blood collections were made. Indomethacin caused no significant change in mean arterial pressure, GFR $(1.03 \pm 0.05$ $\mathrm{ml} / \mathrm{min}$ per $0.1 \mathrm{~kg})$, or $R B F(5.08 \pm .25 \mathrm{ml} / \mathrm{min}$ per $0.1 \mathrm{~kg})$ as compared with high-dose meclofenamate-treated rats. Acidbase parameters and the reduction of urinary $\mathrm{PGE}_{2}$ and $\mathrm{PGF}_{2 \alpha}$ excretion were equally affected by both inhibitors. Total ammonia production was increased $(731 \pm 50 \mathrm{nmoles} / \mathrm{min}$ per $\mathrm{ml}$ GFR) by indomethacin to levels equal to those found in highdose meclofenamate-treated rats. Indomethacin, like meclofenamate, increased the $\mathrm{FE}_{\mathrm{NH}_{3}}$.

$A M A$

Mild AMA, PG intact (Table II; Fig. 4). Hydrochloric acid (2 $\mathrm{mmol} / \mathrm{kg}$ ) was infused over $40 \mathrm{~min}$, which resulted in mild but significant decreases in arterial $\mathrm{pH}$, bicarbonate, and urinary $\mathrm{pH}$ (Table II). Although mean arterial pressures were unchanged, both GFR and RBF decreased from control values (Table II). The arterial and renal venous ammonia concentration and the renal venous, arterial ammonia difference were increased to values greater than those of control, PG-intact, nonacidemic rats. Mild acidemia resulted in more than a twofold increase in total ammonia synthesis as compared with controls $(617 \pm 67$ vs. $281 \pm 19$ nmoles/min per ml GFR; $P$ $<0.01$; Fig. 4). Mild AMA dramatically increased the excretion of $\mathrm{PGE}_{2}$ from $87 \pm 7$ to $256 \pm 42 \mathrm{pg} / \mathrm{min}(P<0.01)$ and $\mathrm{PGF}_{2 \alpha}$ from $191 \pm 19$ to $695 \pm 178 \mathrm{pg} / \mathrm{min}(P<0.01)$ (Table II). The $\mathrm{FE}_{\mathrm{NH}_{3}}$ during mAMA was $51 \pm 3$, a value no different from normal rats. One might have anticipated that the $\mathrm{FE}_{\mathrm{NH}_{3}}$ would increase in mAMA. The urine flow rate dramatically fell and PG excretion significantly increased, however, and as will be



Figure 4. Ammonia production and PG excretion in normal rats and those with mAMA and sAMA. PG depletion was induced with $5 \mathrm{mg} /$ $\mathrm{kg}$ of intravenous meclofenamate. Intergroup differencesiare indicated by the $P$-values above the bars. Corresponding PG excretion can be found in Table II.

discussed below these forces may well underlie the failure to demonstrate an increased $\mathrm{FE}_{\mathrm{NH}_{3}}$.

PGs appear to inhibit renal ammonia synthesis, since acute suppression of their production strikingly stimulates ammoniagenesis. Mild AMA simultaneously stimulated ammonia generation and the production of inhibitory PGs. The following experiments were therefore carried out to define whether a given degree of acidosis can provoke a greater degree of ammoniagenesis if PG synthesis is inhibited.

Meclofenamate plus mild AMA (Table II; Fig. 4). The administration of $5 \mathrm{mg} / \mathrm{kg}$ of meclofenamate $30 \mathrm{~min}$ before the induction of mAMA did not alter RBF, GFR, or the systemic or urinary acid-base response to $\mathrm{HCl}$ loading when compared with PG-intact rats receiving a similar load of acid (Table II; Fig. 4). Arterial $(56 \pm 8 \mathrm{nmol} / \mathrm{ml})$ and renal venous $(126 \pm 7 \mathrm{nmol} / \mathrm{ml})$ ammonia concentrations were less than those seen in PG-intact rats undergoing mAMA $(P<0.05)$, but the renal venous, arterial ammonia differences were the same in both groups. Unlike normal acid-base conditions where high-dose meclofenamate was able to erase PGs from the urine, this dose administered to rats undergoing mAMA could only lower urinary levels to $51 \pm 9 \mathrm{pg} / \mathrm{min}$ and $68 \pm 11$ $\mathrm{pg} / \mathrm{min}$, for $\mathrm{PGE}_{2}$ and $\mathrm{PGF}_{2 \alpha}$, respectively. Prevention of the acid-induced increment in PG synthesis further augmented the increase in ammoniagenesis elicited by mAMA. Total ammonia production in PG-intact rats with mAMA was $617 \pm 67 \mathrm{nmol} / \mathrm{min}$ per $\mathrm{ml} \mathrm{GFR}$ but was $853 \pm 88 \mathrm{nmol} / \mathrm{min}$ per ml GFR $(P<0.05)$ in PG-deplete rats with mAMA (Fig. 4). This increased ammoniagenesis was associated with an increase in urinary ammonia excretion, while the ammonia added to the renal vein was no different than in PG-intact mAMA rats. In fact, the $\mathrm{FE}_{\mathrm{NH}_{3}}$ significantly increased from $51 \pm 3$ to $59 \pm 4 \%(P<0.05)$ in PG-deplete mAMA rats. This 
is similar to the alteration of $\mathrm{FE}_{\mathrm{NH}_{3}}$ seen in PG-depleted normal rats.

sAMA (Table II; Fig. 4). During severe AMA, RBF and GFR slightly but significantly decreased as compared with control rats or rats with mAMA. Despite the increased severity of acidosis, urinary PG excretion did not increase beyond that seen in mAMA (Table II). Arterial and renal venous ammonia concentrations were not greater than values obtained in mAMA but were, of course, greater than those in normal rats. Total ammonia production increased to $833 \pm 102 \mathrm{nmol} / \mathrm{min}$ per $\mathrm{ml}$ GFR, a value that was $30 \%$ greater than that seen in mAMA $(P<0.05)$. The increased ammonia synthesized by the kidney during SAMA exited primarily via the urine, and this was reflected by an increase in the $\mathrm{FE}_{\mathrm{NH}_{3}}(58 \pm 3 \%)$, which is significantly greater than PG-intact normal pH $(P<0.05)$ and PG-intact mAMA $(P<0.05)$.

Meclofenamate plus SAMA. The inhibition of PG synthesis before the administration of acid did not alter mean arterial pressure, RBF, GFR, systemic $\mathrm{pH}$, arterial bicarbonate concentration, urinary $\mathrm{pH}$, or urinary flow rates in comparison with PG-intact SAMA (Table II). PG excretion ( $\mathrm{PGE}_{2}, 29 \pm 8$ $\mathrm{pg} / \mathrm{min} ; \mathrm{PGF}_{2 \alpha}, 67 \pm 13 \mathrm{pg} / \mathrm{min}$ ) was significantly decreased but as in mAMA, measurable amounts were still present in the urine despite high-dose meclofenamate (Table II). In contrast to mAMA, inhibition of PG synthesis did not further augment the ammoniagenic response to sAMA. The rates of addition of ammonia to the renal vein and to the urine were equal in PG-intact and -depleted rats with SAMA.

When total ammonia production was plotted against PGF $_{2 a}$ excretion in normal rats and in rats with mild and severe metabolic acidoses, three distinct slopes were noted $(P<.01$ for normal vs. mAMA; $P<.05$ for mAMA vs. SAMA; Fig.
5). Corresponding correlation coefficients were significant for normal $(P<0.01)$ and mAMA $(P<0.05)$. Clearly, these data suggest that in normal rats and those with mAMA increasing renal net synthesis of $\mathrm{PGF}_{2 \alpha}$ reduces ammonia production. Severe AMA is not influenced by PG synthesis. The statistically significantly different slopes (Fig. 5) indicate that at any given level of $\mathrm{PGF}_{2 \alpha}$ synthesis ammoniagenesis increases with increasing degrees of acidosis.

Acute metabolic alkalosis. Alkalosis lowered the GFR to $0.90 \pm 0.02 \mathrm{ml} / \mathrm{min}$ per $0.1 \mathrm{~kg}(P<.05)$ but $\mathrm{RBF}$ remained unchanged when compared with rats in normal acid-base balance. Urine flow rates were increased $(103 \pm 23 \mu \mathrm{l} / \mathrm{min})$ as was systemic $\mathrm{pH}$, arterial bicarbonate concentration, and urine pH. Arterial ammonia concentration was lower and the renal venous, arterial difference was increased in comparison with values obtained from normal controls. Total ammonia synthesis was not decreased by acute alkalosis although the urinary excretion was diminished $(96 \pm 7$ vs. $140 \pm 13 \mathrm{nmol} / \mathrm{min}$ per $\mathrm{ml}$ GFR; $P<0.05$ ). It follows that the rate of ammonia addition to renal venous blood increased (Table II). The $\mathrm{FE}_{\mathrm{NH}_{3}}$ was $29 \pm 6 \%$, which was significantly lower than normal rats $(50 \pm 5 \%$; $P<0.01)$. Excretion of $\mathrm{PGF}_{2 \alpha}(176 \pm 39 \mathrm{pg} / \mathrm{min})$ and $\mathrm{PGE}_{2}$ $(59 \pm 22 \mathrm{pg} / \mathrm{min})$ were unchanged by alkalosis.

$P G$-deplete rats with $A M A$. Inhibition of PG synthesis did not significantly alter the GFR or RBF but did reduce urine flow rates $(67 \pm 11 \mu \mathrm{l} / \mathrm{min})$ in acutely alkalotic rats (Table II). Arterial $\mathrm{pH}$, bicarbonate concentration, and urinary $\mathrm{pH}$ were not different from values obtained in alkalotic, PG-intact rats. Meclofenamate administration reduced urinary $P G\left(P_{G E}\right.$ and $\mathrm{PGF}_{2 \alpha}$ ) excretion in alkalotic rats to unmeasurable values (Table II). Arterial ammonia concentration was increased to normal $(63 \pm 8 \mathrm{nmol} / \mathrm{ml})$, while the renal venous, arterial

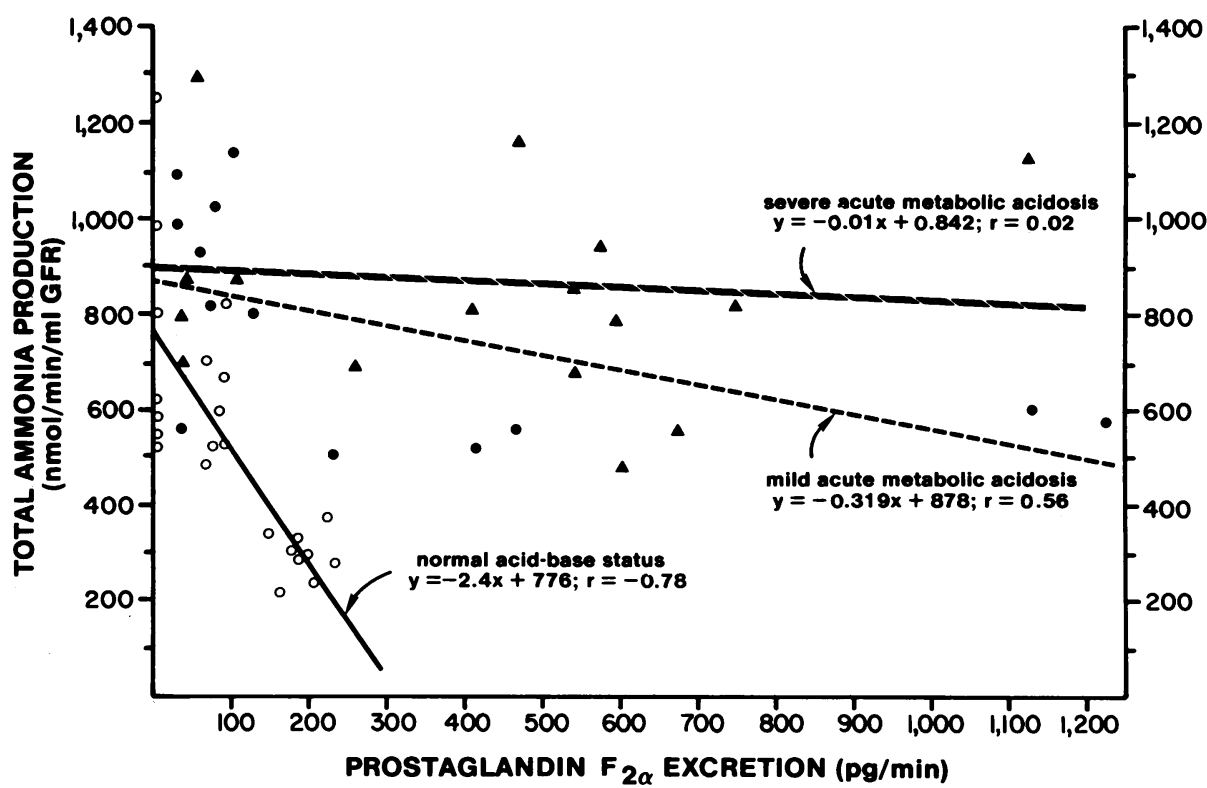

998
Figure 5. Relationship between total ammonia production and urinary PGF $_{2 \alpha}$ excretion in rats under normal acid-base conditions and in those undergoing MAMA and SAMA. (O) and solid line refer to normal acid-base status; $(\bullet)$ and thin broken line, to mild AMA; and $(\Delta)$ and heavy broken line, to severe AMA. 
Table III. Ammonia and PG Production by Incubated Rat Renal Cortical Slices

\begin{tabular}{llll}
\hline Groups & Tissue weight & $\begin{array}{l}\text { Total } \mathrm{NH}_{3} \\
\text { production }\end{array}$ & $\begin{array}{l}\mathrm{PGF}_{2 a} \\
\text { production }\end{array}$ \\
\hline & $m g d r y w t$ & $\mu m o l / g d r y$ weight/h & $n g / m g d r y w t / h$ \\
PG intact (15)* & $18.2 \pm 0.2$ & $240 \pm 22$ & $142 \pm 22$ \\
PG deplete (18) & $16.5 \pm 0.1$ & $309 \pm 15^{\prime \prime}$ & $66 \pm 12^{\prime \prime}$ \\
PG excess (9) & $18.5 \pm 0.2$ & $205 \pm 12^{\prime \prime}$ & $335 \pm 58^{\prime \prime}$ \\
\hline
\end{tabular}

In vitro PG synthesis was inhibited by adding meclofenamate (PG deplete) or stimulated by adding calcium ionophore (PG excess), or vehicle (PG intact).

* The number in parenthesis refers to the number of experiments.

" $P<0.5$, paired $t$ test.

$P$-values refer to the comparison of PGs intact slices with PGs excess or PGs deplete slices.

ammonia differences remained unchanged when PG synthesis was inhibited in alkalotic rats. Total ammonia production increased significantly from $330 \pm 29 \mathrm{nmol} / \mathrm{min}$ per $\mathrm{ml}$ GFR in PG-intact alkalotic rats to $417 \pm 38 \mathrm{nmol} / \mathrm{min}$ per $\mathrm{ml} \mathrm{GFR}$ in PG-deplete, alkalotic rats $(P<0.05)$. The $\mathrm{FE}_{\mathrm{NH}_{3}}$ returned to normal after PG synthesis inhibition $(44 \pm 5 \%)$. The increment in total ammonia synthesis effected by PG inhibition in alkalotic rats was substantially less than the increment produced in normal, nonalkalotic rats by meclofenamate $(87 \mathrm{nmol} / \mathrm{min}$ per ml GFR vs. $485 \mathrm{nmol} / \mathrm{min}$ per $\mathrm{ml} \mathrm{GFR;} P<0.01$ ).

In vitro studies. Pooled renal cortical slices from normal rats were randomly distributed into three media: standard KHB (PG intact), KHB plus meclofenamate (PG depleted), and KHB plus calcium ionophore, to stimulate PG synthesis (PG excess). The in vitro reduction of PG synthesis was associated with increased ammonia production (Table III), albeit not to unmeasurable levels. Indomethacin produced similar results; $\mathrm{PGF}_{2 \alpha}$ synthesis fell from $178 \pm 28$ to $81 \pm 19$ $\mathrm{ng} / \mathrm{g}$ dry wt per $\mathrm{h}$ while $\mathrm{NH}_{3}$ synthesis increased from $221 \pm 30$ to $298 \pm 18 \mu \mathrm{mol} / \mathrm{g}$ dry wt per $\mathrm{h} ; P<0.05$. Calcium ionophore moderately but significantly increased PG production and simultaneously inhibited ammonia synthesis. On acidification of the incubation medium ( $\mathrm{pH} 7.0$ ), no significant changes in ammonia synthesis $(314 \pm 17$ vs. $271 \pm 37 \mu \mathrm{mol} / \mathrm{g}$ dry wt per $\mathrm{h})$ were noted, however, $\mathrm{PGF}_{2 \alpha}$ production increased by $32 \%$ ( $264 \pm 35$ vs. $356 \pm 65 \mathrm{ng} / \mathrm{d}$ dry wt per $\mathrm{h} ; P<0.05$ ).

\section{Discussion}

Although our understanding of how renal ammoniagenesis is controlled has greatly increased over the past 20 years, much remains to be explained. Systemic $\mathrm{pH}$, serum potassium concentration, adrenal steroids, and RBF have been extensively studied and shown to play key regulatory roles (4). The means by which changes in acid-base or potassium balance are translated into salutary alterations in renal ammonia synthesis remain largely unknown. Indeed, it is uncertain whether these effectors act directly on renal metabolic pathways or if a second messenger such as PGs, mediates the observed changes.

PGs are important regulators of RBF, GFR, renin release, and renal salt and water handling (1). The interaction between PGs and renal ammoniagenesis has not, however, been systematically studied. Herein, we report for the first time that PGs are potent inhibitors of renal ammonia synthesis.

We have demonstrated that administration of high doses of PG-synthesis inhibitors to rats with normal blood $\mathrm{pH}$ simultaneously eradicated $\mathrm{PGF}_{2 \alpha}$ and $\mathrm{PGE}_{2}$ from the urine and effected a threefold increase in total ammonia production. The causal relationship between reduced PG synthesis and increased ammonia production is strengthened by the fact that two chemically dissimilar inhibitors, meclofenamate and indomethacin, equally stimulated ammoniagenesis. Additionally, the dose response of ammonia produced to meclofenamate administered revealed a very strong correlation between the fall in PG excretion and the rise in ammonia generation (Fig. 3). Finally, not only did the addition of PG inhibitors to incubated renal cortical slices fully reproduce the stimulation of ammoniagenesis found in vivo, but in vitro stimulation of PG synthesis inhibited basal ammonia production (Table III). This inverse relationship therefore suggests that production of ammonia may be partially but constantly suppressed by the local synthesis of PGs.

Certain insights into the mechanisms by which PGs may influence ammonia synthesis can be gleaned from our data. That in vitro modification of PG synthesis resulted in qualitatively similar changes in ammoniagenesis as seen in vivo, suggests that the PG effect is likely to be independent of hemodynamic changes, GFR, or ambient concentration of glutamine, potassium, calcium, protons, or extrarenal hormones. The independence of the PG effects from renal hemodynamic changes is strengthened by the fact that inhibitors of PG synthesis stimulate ammonia production but tend to reduce RBF and GFR (20). The latter effect ought to diminish, not enhance, ammoniagenesis (21). While the PG-ammonia effect clearly takes place in the cortex, we have yet to identify the exact anatomic site of this interaction.

Calcium may have a more influential role in mediating the interplay between PGs and ammonia synthesis. Calcium ionophore A23187 facilitates cellular uptake of the divalent cation and simultaneously stimulates PG synthesis (22). Hypercalcemia has been variously reported to increase (23), decrease (24), or leave renal ammoniagenesis unchanged (25). However, renal PG production has been consistently shown to vary inversely with the cellular uptake of calcium; nifedipine, the calcium channel blocker, inhibits both processes and calcium ionophore A23187, enhances them (22). Thus, forces regulating renal epithelial cell calcium concentration could influence ammoniagenesis via the intermediation of altered PG synthesis. The role, if any, of calcium-PGs in translating alterations in the concentration of serum electrolytes or hormones into changes in ammoniagenesis remains to be explored. 
Renal ammonia synthesis is critically dependent upon the continued availability of glutamine, the kidney's preferred source of ammonia nitrogen (26). The accessibility of this amino acid is dependent upon its extrarenal production and utilization, delivery to the kidney, and renal epithelial cell uptake and intracellular distribution. It is unlikely that the demonstrated effects of PGs on ammonia synthesis were influenced by extrarenal alterations in glutamine metabolism. Serum glutamine concentration was unchanged after acute administration of $P G$ synthesis inhibitors $(446 \pm 10 \mu \mathrm{M}$ in normal rats vs. $418 \pm 65 \mu \mathrm{M}$ in rats after $1 \mathrm{mg} / \mathrm{kg}$ meclofenamate; unpublished observation) and $R B F$, if changed at all, fell slightly. Thus, the product of $R B F$ and serum glutamine concentration did not increase, which eliminated enhanced substrate delivery as an explanation of how removal of PGs stimulated renal ammoniagenesis. While PGs may influence the cellular uptake of glutamine, neither our studies nor any published work has addressed this potentially important issue.

The cellular effects of PGs are thought to be negotiated primarily at the cell membrane and little is known of any direct intracellular metabolic effects (1). The PGs could inhibit ammoniagenesis by impairing cytosolic and/or mitochondrial reactions involved in stripping nitrogen from glutamine and/ or those concerned with disposing of its carbon skeleton. These possibilities are currently being explored.

In addition to their influence on total renal production, the PGs also modified the distribution of ammonia outflow from the kidney. Inhibition of PG production in normal rats increased ammoniagenesis from $281 \pm 19 \mathrm{nmol} / \mathrm{min}$ per $\mathrm{ml}$ GFR to $766 \pm 87 \mathrm{nmol} / \mathrm{min}$ per $\mathrm{ml} \mathrm{GFR}$ and concomitantly increased the fraction of exiting ammonia that appeared in the urine (i.e., the $\mathrm{FE}_{\mathrm{NH}_{3}}$ ) from $50 \pm 5$ to $63 \pm 8 \%(P<0.05)$. This augmented urinary capture of ammonia occurred in the absence of such factors as aciduria and polyuria, which are known to enhance the $\mathrm{FE}_{\mathrm{NH}_{3}}$. Recent studies describing the medullary trapping of ammonia offer a reasonable explanation for our findings $(27,28)$.

It has been shown that progressive water loss from the glomerular filtrate, as it descends through the increasingly more concentrated medulla, renders remaining fluid more alkaline by increasing the bicarbonate concentration in the descending limb $(27,28)$. The alkalinization converts luminal $\mathrm{NH}_{4}^{+}$to $\mathrm{NH}_{3}$, which in turn passes through the medullary interstitium and is trapped in the relatively more acidic environment of the medullary collecting system $(27,28)$. This proximal tubule-to-loop of Henle-to-collecting duct pathway short-circuits return of $\mathrm{NH}_{3}$ to the cortex and ensures its efficient excretion.

It follows that factors that enhance the concentration of solute in the medullary interstitium ought to enhance the egress of water from the descending limb, thereby augmenting ammonia trapping. The PGs may well increase medullary blood flow $(29,30)$ and inhibit sodium reabsorption by the thick ascending limb (31). It is reasonable to expect that inhibition of PG synthesis would allow more sodium chloride to enter the interstitium and the associated reduction in medullary blood flow would prevent washout of interstitial solute. This scenario could easily explain why indomethacin and meclofenamate both enhance the $\mathrm{FE}_{\mathrm{NH}_{3}}$. Further studies are needed to explore this hypothesis.

While metabolic acidosis and alkalosis are well-known modifiers of renal ammoniagenesis, it was uncertain whether associated changes in PG synthesis influenced this interplay. Indeed, a number of previously published studies suggested that acid-base changes did modify PGs synthesis (5-10).

Studies by Gulyassay and Edelman (8) as well as others (5-7) showed that acidification of the serosal media bathing toad bladders inhibited the hydro-osmotic effect of ADH (57). Most recently, Forrest et al. (9) confirmed these results and further noted that serosal acidification increased $\mathrm{PGE}_{2}$ production. The addition of meclofenamate or indomethacin suppressed PG production by the acidified bladder and restored the hydro-osmotic effect of ADH. In concert with these in vitro studies, Beck and $\mathrm{Kim}$ (10) showed that in comparison with normal rats, those made chronically acidotic could not appropriately elevate their urinary osmolality in response to administered vasopressin. These observations strongly suggest that modest degrees of metabolic acidosis stimulate PG synthesis and the latter evoke physiologic changes.

We demonstrated that $40 \mathrm{~min}$ after the induction of mAMA, total renal ammonia production by anesthetized rats more than doubled, while excretion of $\mathrm{PGE}_{2}$ and $\mathrm{PGF}_{2 \alpha}$ increased by 2.9-3.6-fold (Table II). Since our studies of normal rats indicated that PGs inhibited ammoniagenesis, we reasoned that acidosis-stimulated ammonia synthesis must reflect the algebraic sum of direct acid enhancement and the indirect inhibition of augmented PG synthesis. Reduction of acid-stimulated PG production with various doses of meclofenamate caused further enhancement of ammonia production (Fig. 5), which corroborated the above postulate. Thus, over a rather narrow range of metabolic acidosis (serum $\mathbf{H C O}_{3}$ : $18.0 \pm 0.4 \mathrm{mM}$, arterial $\mathrm{pH}: 7.29 \pm 0.01$ ), inhibitor-induced alterations in PG excretion changed total ammonia production by $\sim 50 \%$ (Fig. 4). Failure of more severe degrees of hypobicarbonatemia to further enhance PG synthesis suggests that maximal stimulation was achieved when the serum bicarbonate concentration reached $18 \mathrm{mM}$. Furthermore, it would appear that the direct stimulatory effect of the more severe degrees of acidosis are powerful enough to neutralize the inhibitory action of stimulated PG synthesis. This situation seems analogous to the diminishing effect of inhibited PG synthesis in augmenting the hydro-osmotic effect of increasing doses of ADH (32). This hormone simultaneously enhances water reabsorption from the collecting duct while stimulating PG synthesis, which, in turn reduces the magnitude of ADH's effect. As in severe acidosis, the direct action of high doses of the hormone is no longer enhanced by PG synthesis inhibition $(32,33)$.

As in normal rats, the PGs strongly influenced both total ammonia production and the $\mathrm{FE}_{\mathrm{NH}_{3}}$ in mAMA. Meclofenamate simultaneously stimulated total synthesis and increased the 
$\mathrm{FE}_{\mathrm{NH}_{3}}$ by $8 \%$ (Table II). As with normal rats, the enhanced excretion occurred in the absence of a fall in urinary $\mathrm{pH}$, and urinary volume decreased, which ought to diminish, not increase, the $\mathrm{FE}_{\mathrm{NH}_{3}}$. We would again speculate that the diminution in medullary blood flow and enhanced solute entry into the medulla consequent to inhibition of PG synthesis, enhances the medullary solute concentration and ammonia trapping.

The mechanism by which acidosis stimulates renal PGs synthesis was not addressed by our studies. Future studies will evaluate the influence of acidosis on arachadonic acid mobilization and on the conversion of the fatty acid into the various PGs.

After $40 \mathrm{~min}$ of sustained acute metabolic alkalosis total ammonia synthesis was not changed but the alkaline urinary $\mathrm{pH}$ strikingly reduced the $\mathrm{FE}_{\mathrm{NH}_{3}}$ from the normal $50 \pm 5$ to $29 \pm 6 \%$ (Table II). Presumably, a longer duration of alkalosis is required to inhibit ammonia synthesis.

AMA had no effect on PG excretion. However, inhibition of PG synthesis, was associated with a small but significant increase in total ammonia production, which indicates that PGs also modulate ammoniagenesis during mild alkalemia. It should be noted that virtually the entire increment in ammonia production caused by meclofenamate was excreted in the urine. The increase in the $\mathrm{FE}_{\mathrm{NH}_{3}}$ from $29 \pm 6$ to $44 \pm 5 \%$ enabled the alkalotic kidney to produce and excrete an additional 88 $\mathrm{nmol} / \mathrm{min}$ per $\mathrm{ml} \mathrm{GFR}$. Inhibition of PG synthesis in normal rats increased ammoniagenesis by $485 \mathrm{~nm} / \mathrm{min}$ per $\mathrm{ml}$ GFR and in mildly acidotic rats by $236 \mathrm{nmols} / \mathrm{ml}$ GFR but similar inhibition of PG synthesis only increased ammonia production by $88 \mathrm{nmols} / \mathrm{min}$ per $\mathrm{ml} \mathrm{GFR}$ in alkalotic rats. Thus, alkalosis appears to curb meclofenamate stimulation of ammoniagenesis.

Our concept of the interplay between PGs and ammonia synthesis is summarized as follows. The PGs appear to act as negative-feedback inhibitors of ammonia synthesis, functioning in a manner similar to that observed in other biological systems. A number of stimuli such as vasopressin, angiotensin II, and acidosis exert primary stimulatory effects on the kidney, which causes reabsorption of water, vasoconstriction or enhances ammoniagenesis; these stimuli increase PG synthesis, which in turn inhibit the direct effect of the stimuli. Thus, augmented release of PGs inhibits the hydro-osmotic effect of $\mathrm{ADH}$, causes vasodilatation by countering angiotensin II's effect, and now we have demonstrated that PGs inhibit ammonia synthesis. If the PGs effect is eradicated, the primary effect on the kidney is enhanced. However, pharmacologic doses of the primary effectors, e.g., $\operatorname{ADH}(32,33)$ or angiotensin II $(34,35)$ can override the inhibitory effect of PGs as we have noted in severe metabolic acidosis. This regulatory function of PGs on ammonia synthesis appears to act most efficiently during normal acid-base conditions and with mild changes of $\mathrm{pH}$.

We conclude that PGs inhibit ammonia synthesis. It remains to be shown whether stimuli other than mAMA influence ammoniagenesis by altering renal PG synthesis.

\section{Acknowledgments}

We appreciate the excellent secretarial assistance of Ms. Elsie M. Williams.

This work was supported by a grant from the Southeastern Chapter of the National Kidney Foundation and a Clinical Investigation Award from the National Institutes of Health (1 K08 AM01211-01).

\section{References}

1. Dunn, M. J., and V. L. Hood. 1977. Prostaglandins and the kidney. Am. J. Physiol. 233:F169-F184.

2. Berl, T., and R. W. Schrier. 1973. Mechanism of the effect of prostaglandin $E_{1}$ on renal water excretion. J. Clin. Invest. 52:463-471.

3. Berl, T., A. Raz, H. Wald, J. Horowitz, and W. Czaczkes. 1977. Prostaglandin synthesis inhibition and the action of vasopressin: studies in man and rat. Am. J. Physiol. 232:F529-F537.

4. Tannen, R. L. 1978. Ammonia metabolism. Am. J. Physiol. 235:F265-277.

5. Bentley, P. J. 1958. The effects of neurohypophyseal extracts on water transfer across the wall of the isolated urinary bladder of the toad Bufo marinus. J. Endocrinol. 17:201-209.

6. Rasmussen, H., I. L. Schwartz, M. A. Schoessler, and G. Hochster. 1960. Studies on the mechanism of action of vasopressin. Proc. Natl. Acad. Sci. USA. 46:1278-1287.

7. Orloff, J., and J. S. Handler. 1962. The similarity of effects of vasopressin, adenosine-3',5'-phosphate (cyclic AMP) and theophylline on the toad bladder. J. Clin. Invest. 41:702-709.

8. Gulyassy, P. F., and I. S. Edelman. 1965. Hydrogen ion dependence of the antidiuretic action of vasopressin, oxytocin and deaminooxytocin. Biochim. Biophys. Acta. 102:185-197.

9. Forrest, J. N., C. J. Schneider, and D. B. P. Goodman. 1981. Role of prostaglandin $E_{2}$ in mediating the effects of $\mathrm{pH}$ on the hydroosmotic response to vasopressin in the toad urinary bladder. $J$. Clin. Invest. 69:499-506.

10. Beck, N., and H. P. Kim. 1975. Effect of acute metabolic acidosis on vasopressin-dependent cyclic AMP in rat kidney. Endocrinology. 93:1552-1558.

11. Kaufman, J. M., N. J. Siegel, and J. P. Hayslett. 1975. Functional and hemodynamic adaptation to progressive renal ablation. Circ. Res. 36:286-293.

12. Narins, R. G., M. Emmett, J. Rascoff, E. R. Jones, and A. S. Relman. 1982. Effect of acute acid-base changes on in vivo total ammonia synthesis in the rat. Contrib. Nephrol. 31:47-52.

13. Narins, R. G., and A. S. Relman. 1974. Acute effects of acidosis on ammoniagenic pathways in the kidneys of the intact rat. Am. J. Physiol. 227:946-949.

14. Kurahasi, K., A. Ishihara, and H. Uehann. 1972. Determination of ammonia in blood plasma by an ion exchange method. Clin. Chem. Acta. 42:141-149.

15. Kaplan, A. 1972. Urea nitrogen and urinary ammonia. In Standard Methods in Clinical Chemistry. S. Mectes, editor. Academic Press, Inc., New York. 5:245-247.

16. Beck, T. R., A. Hassid, and M. J. Dunn. 1982. Desamino-Darginine vasopressin induced fatty acid cyclooxygenase activity in the renal medulla of diabetes insipidus rats. J. Pharm. Exp. Ther. 221:269274.

17. Wolf, A. W. 1941. Total renal blood flow at any urinary flow or extraction fraction. Am. J. Physiol. 133:496-497. 
18. Zar, J. H. 1974. Biostatistical analysis. W. D. McElroy and C. P. Swanson, editors, Prentice Hall, Inc., Englewood Cliffs, NJ. 82104.

19. Dunn, M. J., H. P. Greely, H. Valtin, L. B. Kinter, and R. Beeuwkes III. 1978. Renal excretion of prostaglandins $E_{2}$ and $F_{2 \alpha}$ in diabetes insipidus rats. Am. J. Physiol. 4:3624-3627.

20. Roman, R. J., and M. L. Kauker. 1978. Renal effects of prostaglandin synthetase inhibition in rats: micropuncture studies. $\mathrm{Am}$. J. Physiol. 235:F111-F118.

21. Lemieux, G., P. Vinay, and P. Carter. 1974. Renal hemodynamics and ammoniagenesis. J. Clin. Invest. 53:884-894.

22. Zenser, T. V., and B. B. Davis. 1978. Effects of calcium on prostaglandins $\mathrm{E}_{2}$ synthesis by rat inner medullary slices. Am. J. Physiol. 235:F213-F218.

23. Richet, G., R. Ardaillou, C. Amiel, and M. Leastre. 1963 Acidification de l'urine par injection intraveinuse de sels de calcium. J. Urol. 69:373-378.

24. Heinemann, H. D. 1963. Reversible defect in renal ammonium excretion in patients with hypercalcemia. Metab. Clin. Exp. 12:792795.

25. Mitnick, P., A. Greenberg, T. Coffman, E. Kelepouris, C. J. Wolf, and S. Goldfarb. 1982. Effects of two models of hypercalcemia on renal acid-base metabolism. Kidney Int. 21:613-617.

26. Van Slyke, D. D., R. A. Phillips, P. B. Hamilton, R. M. Archibald, P. H. Futcher, and A. Hiller. 1943. Glutamine as a source material of urinary ammonia. J. Biol. Chem. 150:401-402.

27. Buerkert, J., D. Martin, and D. Trigg. 1982. Ammonium handling by superficial and juxtamedullary nephrons in the rat. Evidence for an ammonia shunt between the loop of Henle and the collecting duct. J. Clin. Invest. 70:1-12.

28. Sajo, I. M., M. B. Goldstein, H. Sonnenberg, B. J. Stinebaugh, D. R. Wilson, and M. L. Halperin. 1981. Studies of ammonia addition to tubular fluid in rats with chronic metabolic acidosis. Kidney Int. 20:353-358.

29. Lifschitz, M. D. 1981. Prostaglandins and renal blood flow. In vivo studies. Kidney Int. 19:781-786.

30. Larsson, C., and E. Änggard. 1974. Increased juxtamedullary blood flow in stimulation of intrarenal prostaglandin biosynthesis. Eur. J. Pharmacol. 25:326-334.

31. Stokes, J. B. 1979. Effect of prostaglandin $E_{2}$ on chloride transport across the rabbit thick ascending limb of Henle. Selective inhibition of the medullary portion. J. Clin. Invest. 64:495-502.

32. Schlondorff, D., C. P. Carvounis, M. Jacoby, J. A. Satriano, and S. D. Levine. 1981. Multiple sites for interaction of prostaglandins and vasopressin in toad urinary bladder. Am. J. Physiol. 241:F625F631.

33. Culpepper, R. M., and T. E. Andreoli. 1983. Interactions among prostaglandin $E_{2}$, antidiuretic hormone, and cyclic adenosine monophosphate in modulating $\mathrm{Cl}^{-}$absorption in single mouse medullary thick ascending limbs of Henle. J. Clin. Invest. 71:1588-1600.

34. Negus, P., R. L. Tannen, and M. J. Dunn. 1976. Indomethacin potentiates the vasoconstrictor actions of angiotensin II in normal man. Prostaglandins. 12:175-180.

35. Aiken, J. W., and J. R. Vane. 1973. Intrarenal prostaglandin release attenuates the renal vasoconstriction activity of angiotensin. $J$. Pharmacol. Exp. Ther. 184:678-687. 